\title{
HISTORICALLY WHITE UNIVERSITIES AND THE WHITE GAZE: CRITICAL REFLECTIONS ON THE DECOLONISATION OF THE LLB CURRICULUM ${ }^{1}$
}

\author{
by Mankhuwe Caroline Letsoalo* \& Zenia Pero**
}
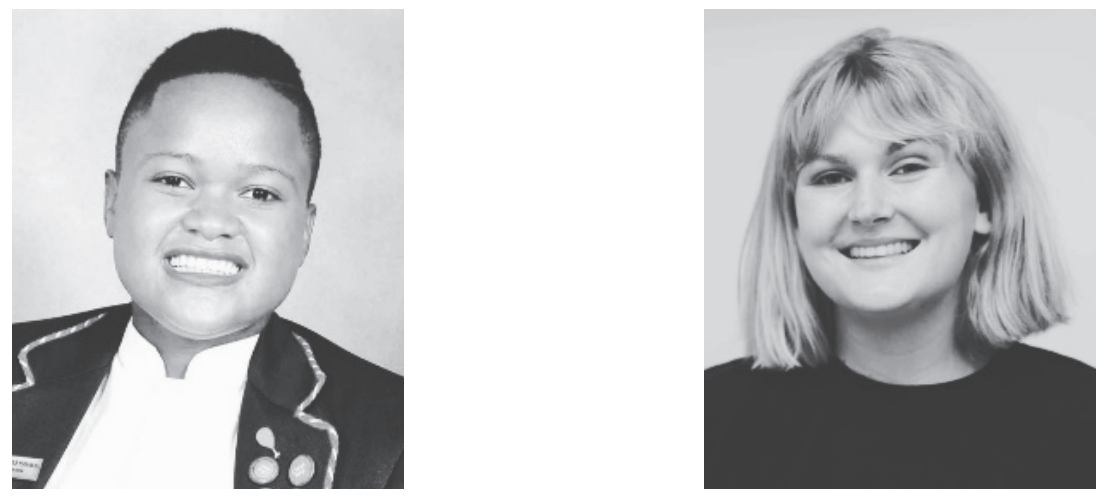

The white gaze, given the power of the ocular metaphor in Western culture, is an important site of power and control, a site that is structured by white epistemic orders and that perpetuates such orders in return. 2

\section{Abstract:}

The (most recent) call for curriculum decolonisation came at the height of student protests such as \#feesmustfall and \#afrikaansmustfall. In the University of Pretoria's Curriculum Transformation Framework document, the University identified four drivers of curriculum transformation, namely, responsiveness to social context; epistemological diversity; renewal of pedagogy and classroom practices; and an institutional culture of openness and critical reflection. The content of these drivers mirror what is needed to engage in decolonisation of curricula. In the spirit of these protests that led to the conceptualisation of decolonised higher education, the authors of this

* Mankhuwe Caroline Letsoalo III is an LLM research candidate at the University of the Free State. She holds an LLB from the University of Pretoria.

** Zenia Pero is an LLM candidate in the Socio-economic rights program offered at the University of Pretoria. She holds a BA Law and LLB obtained at the University of Pretoria.

1 This article focuses in particular on the University of Pretoria.

2 G Yancy Whiteness and the return of the 'black body' (PhD Thesis, Duquesne University, 2005) 37. 
article critically reflect on the institutional landscape of historically white universities. The authors employ the term 'white gaze' to highlight how historically white universities respond to calls for decolonisation, often substituting this call with transformation. The purpose of this article is to re-contextualise the need for decolonisation at historically white universities.

\section{Introduction}

The call for curriculum decolonisation came at the height of student protests such as \#feesmustfall and \#afrikaansmustfall in 2015 and 2016. In the spirit of these protests that led to the conceptualisation of decolonised higher education, the authors of this article critically reflect on the institutional landscape of historically white universities, particularly the University of Pretoria (UP). Following the protests, the University of Pretoria called a Lekgotla between management and student leaders to discuss how it would respond to the students' demands. What followed, is the University of Pretoria's Curriculum Transformation Framework document. In this framework document the University identified four drivers of curriculum transformation, namely, responsiveness to social context; epistemological diversity; renewal of pedagogy and classroom practices; and an institutional culture of openness and critical reflection.

The key considerations of the drivers are explained further in the curriculum framework document. The focus areas of the first driver are: prioritising social transformation, retrieving and foregrounding historically and presently marginalised narratives, voices and subjugated knowledge, as well as the critical examination of the role of race, socio-economic class, gender, sexuality, and culture. ${ }^{3}$ Encouraging epistemic diversity, recuperating African knowledges, and honestly and critically reckoning with the histories of all disciplines fall within the scope of the driver on epistemic diversity. ${ }^{4}$ The focus of the driver on the renewal of pedagogy and classroom practices includes: addressing the invisibility of certain groups, pursuing inquiry-led teaching and learning, and equipping students with skills. ${ }^{5}$ Lastly, in addressing the institutional culture at UP, the focus is placed on advancing an intellectual culture of critical reflection, accelerating transformation of academic staff, reviewing and redefining the identity of the university, and dismantling institutional hierarchies. ${ }^{6}$

3 UP Curriculum Transformation Framework 2.

4 Transformation Framework (n 3 above) 3.

5 Transformation Framework (n 3 above) 4.

6 Transformation Framework (n 3 above) 5. 
It is, of course, important to note that the term 'decolonisation' is used once in this framework document. 'Decolonising and democratising of the curriculum' are used in conjunction with one another, ${ }^{7}$ but further throughout the document the word 'transformation' is used as an alternative. How this project is called is important. Are transformation and decolonisation interchangeable terms? The article argues that the terms may overlap, but have fundamentally different core aims and outcomes; moreover, decolonisation requires commitment. Historically white universities must, for this very reason, heed caution when engaging with framework documents like the one from UP. The caution is not because of decolonisation itself, but one that stems from intention and commitment to decolonisation which might be lacking on the part of role-players at a University. There is the risk to subsume decolonisation as an academic mini-industry which lacks substance, in other words, there is a chance of colonising decolonisation itself. ${ }^{8}$ The argument here is the need for caution through exploring the term 'white gaze', a popular term in discourse on African American Literature which encapsulates black lived experience in white spaces, ${ }^{9}$ as a critical lens to unpack how a historically white university, such as UP, responds to calls for transformation and decolonisation. The purpose of this article thus is to critique the approach of transformation as/without decolonisation, to provide a cautionary tale of falling into the trap of the white gaze, and to reemphasise, re-contextualise and essentially decolonise the need for decolonisation at historically white universities.

\section{Meaning of a decolonised law curriculum}

To begin with, there is a need to unpack what a decolonised curriculum entails by first distinguishing between three concepts: transformation, Africanisation and decolonisation. Transformation entails altering practices within a system, or introducing new practices to achieve certain goals, referred to as transformative goals often addressing social, political and economic issues. For the LLB curriculum, of particular importance is the phrase 'transformative constitutionalism' as coined by American legal scholar Karl Klare. ${ }^{10}$ Transformative constitutionalism involves the alteration of social,

7 Transformation Framework (n 3 above) 1.

8 T Madlingozi 'Decolonising decolonisation with E'skia Mphahlele' 1 November 2018 https: //www.newframe.com/decolonising-decolonisation-mphahlele/ (July 2019).

9 This metaphor is prominent in the works by WEB Du Bois The souls of black folk (1903); J Baldwin Nobody knows my name (1961); T Morrison The bluest eye (1970) and T Coates Between the world and me (2015).

10 KE Klare 'Legal culture and transformative constitutionalism' (1998) 14 South African Human Rights Law Journal 198. 
political, and economic frameworks under a constitutional dispensation. ${ }^{11}$ This entails that transformation is subject to and often usurped by constitutional provisions. Africanisation calls for the inclusion of more local content in practices, and can be seen as part of either transformation, where one includes epistemic diversity as a goal of transformation, and could also be seen as part of decolonisation where decolonisation entails the 'un-doing' of the intellectual colonisation of ideas that were forced upon and imposed on colonised peoples. ${ }^{12}$

Transformation operates in a limited school of thought and parameters, for example where colonial provisions and practices form part of the constitutional dispensation, or where certain systems of law are favoured over others. Transformation does not always amount to decolonisation, depending on the strategies utilised as will manifest later in the article. Africanisation is a useful strategy to transform and decolonise and it is arguably an effective tool to respond to the violence of colonisation and can potentially bring about epistemic justice and diversity. Fanon cautions that to Africanise without decolonising may lead again to the assimilation of colonial systems and practices. ${ }^{13}$

Decolonisation is a process of conducting research in such a way that the worldviews of those who have suffered a long history of oppression and marginalisation are given space to communicate from their frames of reference, assumptions and perspectives. Decolonisation is not an event but an on-going process that involves creating and consciously using various strategies to liberate the colonised mind. Ngugi wa Thiong'o submits that a 'captive mind' is incapable of partaking in decolonial projects hence one needs to undergo the process of decolonising the mind. ${ }^{14}$ This involves the restoration and development of indigenous cultural practices, thinking patterns, values and beliefs and the birth of new lifestyle and intellect that contributes to the encroachment and empowerment of Africa. ${ }^{15}$

Laenui identifies the following five phases in the process of decolonisation: Rediscovery and recovery, mourning, dreaming, commitment and action. ${ }^{16}$ Rediscovery and recovery is the process whereby colonised peoples rediscover and recover their own history, culture, language, identity and interrogating the captive mind.

11 Klare (n 10 above) 198.

12 Ngũgĩ wa Thiong'o Decolonising the mind: The politics of language in African literature (1981) 9-10.

13 F Fanon Wretched of the earth (1961) 23.

14 B Chilisa Indigenous research methodologies (2012) 8.

15 T Serequeberhan 'The Critique of eurocentrism and the practice of African philosophy' in PH Coetzee \& APJ Roux (eds) The African philosophy reader 2ed (2003) 75.

16 Chilisa (n 14 above) 8. 
Mourning refers to the process of lamenting the on-going assault on the colonised identities and social realities. Dreaming is the phase of decolonising the mind - the colonised invoke their histories, worldviews, and indigenous knowledge systems to theorise and imagine alternative possibilities, in this instance a different curriculum. Commitment is when academics and scholars become political activists who demonstrate the commitment to include the othered voices, in this case, in the university curriculum. Action is the phase where dreams and commitments translate into strategies of decolonisation. ${ }^{17}$

Smith identifies the elements of decolonisation - deconstruction and reconstruction, self-determination and social justice, ethics and critique. ${ }^{18}$ Deconstruction and reconstruction concerns discarding false narratives regarding indigenous knowledges, and interrogating distortions of people's life experiences. Self-determination and social justice relate to the struggle of the colonised and their journey in seeking legitimacy for knowledge that is embedded in their own histories, experiences and ways of viewing reality. In this context, ethics relates to the formulation, legislation and dissemination of ethical issues related to the protection of indigenous knowledge systems. ${ }^{19}$ Critique concerns a critical thinking of colonial method in our curricula that continues to deny space and reject inclusion of voices of the others.

For the purpose of this article, arguably there are three strategies that may be a useful starting point in the decolonisation of legal education. These are the inclusion of African jurisprudence, the teaching of indigenous law, as discussed by Himonga and Diallo, ${ }^{20}$ and the pluriversality between legal fields and theories.

\section{African jurisprudence}

John Murungi submits that to know what it is to be an African lawyer necessarily entails to know what it is to be African and 'what is at stake in being African'. ${ }^{21}$ He also critiques the current legal education for its failure in training its legal scholars to be African legal scholars. He submits that 'the well-being of Africa ... must be the cornerstone of legal education in Africa'. 22 He also rejects the narrative that Africa did not have a legal system before colonisation as the word

17 Chilisa (n 14 above) 8.

18 L Smith Decolonising methodologies: Research and indigenous peoples (1999) 12.

19 L Le Grange 'Decolonising the university curriculum' (2016) 30 South African Journal of Higher Education 4.

20 C Himonga \& $F$ Diallo 'Decolonisation and teaching law in Africa with special reference to living customary law' (2017) 20 Potchefstroom Electronic Law Journal 7.

21 J Murungi An introduction to African legal philosophy (2013) 1-9.

22 Murungi (n 21 above) 8. 
African qualifies jurisprudence and when adequately understood one can see the pluriversality between different schools of thought. African legal systems, much like all legal systems, are founded on the principle of social cohesion and collective justice which is different from the individualistic approach in the English system.

\section{The teaching of indigenous law}

'Living customary law' is the law that governs the legal relations of people who are subject to a given system of customary law in their day-to-day life. Otherwise known as indigenous law, this refers to law and knowledge inherent in the knowledges of indigenous people, and as opposite to the law that is currently practised and that had been planted and developed here through conquest and colonisation.

Indigenous law represents the practices or customs observed and invested with binding authority by those who observe it and its unwritten legal ideas and knowledge. Indigenous law is passed down from one generation to the next orally. ${ }^{23}$ This store of knowledge is uniquely African in the sense that though not insulated from global conditions, its evolution is shaped within changing African social, economic and political contexts. ${ }^{24}$ Moreover, because of its oral nature and flexibility, indigenous law can readily and easily be adjusted to meet the varied needs of justice in a decolonised context. Indigenous law must, therefore, be taught in all law faculties or law schools and at appropriate levels of the law degree that enable students to comprehend the significance and complexity of the subject within the constitutional frameworks.

\section{Pluriversality between legal theories and fields.}

The major legal theoretical framework within which law is taught, is hugely influenced by English and Roman-Dutch common law which follows formalist and positivist legal approaches. These approaches separate legal rules from 'non-legal normative considerations of morality or political philosophy', ${ }^{25}$ which is a hindrance to legal decolonial projects. Legal pluralism must be the cornerstone of the curriculum. Legal pluralism is the coexistence of distinctive legal systems. To claim that the law exists in a vacuum would not only be an illusion but also a myth as far as legal history is concerned. Areas of law must not be taught and learned distinctively but rather

25 B Leiter 'Legal formalism and legal realism: What is the issue?' (2010) 2 Cambridge University Press 111. 
modules must be taught holistically and pluriversally. Pluriversality is conceived by the theory of pluralism and highly entrenched in the notion of cultural relativism which is the objective analysis of knowledge systems; it contrasted with ethnocentrism. ${ }^{26}$ The teaching and study of law in a decolonised context should aim to bring together contributions from various disciplines to focus on regulatory practices embodied by law in all its manifestations.

\section{UP Framework document and decolonisation}

As Tuck and Yang observe 'decolonisation is not a metaphor', 27 within the UP framework document there are a few concrete markers that indicate its alignment with decolonisation. It encourages 'epistemic diversity and pluriversality between different intellectual and cultural heritages', 28 and 'not merely adding new voices and theories but reconceptualising the way in which knowledges and sources of knowledge are organised, valued and represented within disciplines and subject areas'.29 These may be read as aligning itself to some of the core tenets to decolonising legal education earlier highlighted. However, a foreseeable problem in historically white universities, is the institutional culture. The framework acknowledges the problem and the need for the university to confront it when it notes as follows:

Honestly and critically reckoning with the histories of all disciplines and dominant traditions within disciplines to examine their underlying colonial biases and exclusionary cultural norms at the intersections of race, gender, sexuality and class, as well as the complicity of disciplinary knowledges with various forms of violence and oppression over time. This involves, among others, the acknowledgment that even those few historically white universities that admitted a limited number of black students operated on the principle of racial segregation and that black people were mostly excluded from Higher Education, bar the Bantustan universities and two universities set aside for 'coloured' and 'Indian' students. ${ }^{30}$

The danger then is not the project of decolonisation, but the fact that the proposals in the framework themselves have two possible outcomes. The first possible outcome is a successful challenge to the norm of whiteness through, in particular, the use of African jurisprudence, and the promotion of indigenous knowledge. ${ }^{31}$ The

26 B Bizumic \& J Duckitt 'What is and is not ethnocentrism? A conceptual analysis and political implications' (2012) Political Psychology 33:6 887.

27 E Tuck \& KW Yang 'Decolonisation is not a metaphor' 1 (2012) Indigeneity, Education \& Society 1-40.

28 Transformation Framework (n 3 above) 3.

29 Transformation Framework (n 3 above) 4.

30 Transformation Framework (n 3 above) 3.

31 J Murungi 'The question of an African jurisprudence: Some hermeneutic reflections' in K Wiredu (ed) A companion to African philosophy (2005) 521. 
second possibility, is that these proposals could simply assimilate African concepts into the Eurocentric system. The colonisation or recolonisation of decolonisation. ${ }^{32}$

What should be clear then is that decolonisation is not a metaphor for change. Approached in this way decolonisation itself will still reaffirm the structure of white supremacy and colonialism. ${ }^{33}$ Decolonisation requires the system itself to be dismantled, interrogated, thereby no longer allowing the structures that affirm colonialism to survive. ${ }^{34}$ If we were to simply teach indigenous law as equal to our current euro-centric law, without interrogating the role it had played in racism, colonialism, and oppression, then that is not decolonisation. ${ }^{35}$

Consequently, the problem lies in the interpretation of transformation as/and decolonisation at historically white universities where frameworks are still left vague in its conceptualisation of what can and must happen. The distinction between transformation and decolonisation will widen, depending on the commitment to the interpretation of transformation in the document as decolonisation. The interpretation thereof will be influenced by the white gaze, which is explored in the ensuing section.

\section{The historically white university and the white gaze}

George Yancy, a philosopher from the United States of America, sought to theorise on the lived and embodied impact of how race operates socially and epistemologically. ${ }^{36}$ He gives us an example of an elevator occupied by himself, well dressed, and a white woman. The white woman does not 'see' Yancy, but she sees his black body. ${ }^{37}$ What she sees is the characterisation of black men by media, film, public officials rendering his body supersaturated with meanings constructed by whiteness. ${ }^{38}$ Whiteness renders all things that do not ascribe to, appease, and assimilate to whiteness as 'other'. ${ }^{39} \mathrm{Her}$ gestures, her pulling on her purse, her body language, immediately indicate her discomfort at seeing a black man and indicate her

2 Madlingozi (n 8 above) 1.

33 Tuck \& Yang (n 27 above) 9.

34 Tuck \& Yang (n 27 above) 9.

35 Murungi (n 31 above) 521.

36 G Yancy 'Elevators, social spaces, and racism: A philosophical analysis' (2008) 8 Philosophy and social criticism 846.

37 As above.

38 As above.

39 As above. 
discomfort at occupying the space with him. ${ }^{40}$ Yancy did not have to do much in order for his existence, his wants and his intentions, to live within the imagination of this white woman. ${ }^{41}$ Yancy's elevator example exposes the social microcosm of racism, and the ways in which whiteness and racism permeate even the most passive of spaces. ${ }^{42}$ In 'Black bodies, White Gazes' Yancy considers the murder of Eric Garner by white police officers - an instance where the white gaze literally asphyxiated a black male body. ${ }^{43}$ He asks what it is about Eric Garner screaming that he cannot breathe while being held down by the white police officer that does not warrant a sympathetic response. ${ }^{44}$ Did they hear his cries? Did they see and hear his attempts at justifying his actions, his existence? If they heard and saw him, what justifications existed in their minds to ignore him?

This is the power of the white gaze in society, and the power thereof in white spaces. ${ }^{45}$ Historically white universities institutionalised whiteness, racism, and in so doing institutionalised the ocular metaphor of the white gaze. ${ }^{46}$ Arguably, this is as a result of the institutional history of racial divisions entrenched at Universities, especially through policies under the apartheid government. ${ }^{47}$ Specifically legal constraints were put into place to prevent institutions from allowing other race groups to enrol at institutions designated for another. ${ }^{48}$ Rigid distinctions were made between white students and 'the others'. Historically white universities have inherited a legacy from apartheid and played a crucial role in the act of racial subordination. ${ }^{49}$

This legacy continues. As recently as 2007 the UP allowed a 'student organisation to campaign using extremely offensive and racist posters which stated (in Afrikaans) 'Proudly Afrikaans, Proudly White'; 'Afrikaner Studentebond, a Light in the Darkness' and 'White, Whiter, Tuks'. ${ }^{50}$ Fees Must Fall and Afrikaans Must Fall in recent years brought the institutionalisation of racism and whiteness to the fore. These protests culminated in several court cases unpacking exactly

40 Yancy (n 36 above) 850.

41 Yancy (n 36 above) 851.

42 Yancy (n 36 above) 852.

43 G Yancy Black bodies, white gazes: The continuing significance of race in America (2008) 4.

44 Yancy (n 43 above) 4

45 We rely on African American Literature to draw parallels between white hegemonies which persists after liberatory struggles.

46 Yancy (n 43 above) 6.

47 I Bunding 'The higher education landscape under apartheid' in N Cloete, P Maassen, et al (eds) Transformation in higher education (2006) 36.

48 Bunding ( 47 above) 37.

49 T Madlingozi 'Confronting and dismantling institutional racism in the Faculty of Law, University of Pretoria' in C Heyns and H Visser (eds) Transformation at the Faculty of Law, University of Pretoria (2007) 32.

50 Madlingozi (n 49 above) 32. 
the role of Afrikaans at a post-apartheid university, a direct question as to the legacy of racism and whiteness at universities.

Though the universities themselves are seen as racially neutral, or at least diverse in its constituency, the protests were met with violence - they were met with the white gaze. The demands of students were not initially looked at. Rather the students were seen through the ocular metaphor - a demanding force that would disrupt the non-racial utopia perceived to exist. Teargas ensued; interdicts were issued. And then, Lekgotlas were established and frameworks for curriculum transformation were created. Is it possible for the institutional culture to shift so easily from violence to acceptance and commitment? Unlikely. The white gaze need not be outwardly violent, as shown in Yancy's elevator example. The objectification that comes with the white gaze also manifests itself in tacit, but equally violent, ways. ${ }^{51}$ It involves a majority of white academic staff, a lecturer expecting less of black students because the merits and standards for greatness are still defined through 'whiteness', ${ }^{2}$ and invisibilising black academics where they dare not assimilate whiteness. ${ }^{53}$

\section{Conclusion: Decolonising legal education and confronting the white gaze - a cautionary tale}

At the outset of this article we aimed to critique the approach of transformation as/without decolonisation, to provide a cautionary tale of falling into the trap of the white gaze, and to re-emphasise, re-contextualise and essentially decolonise the need for decolonisation at historically white universities. The UP framework document for curriculum transformation is an essential tool in decolonising legal education especially in a historically white university as it recognises the epistemicide that still manifests itself at the institution and further gives in depth strategies to achieve epistemic justice which can ultimately bring about decolonisation of the law curriculum. Some of the strategies undertaken in the framework document align with the research and approaches to decolonisation which we consulted. In particular the strategies from the framework document relate to pluriversality, epistemic justice, promotion of African jurisprudence and the promotion of indigenous knowledge. Although 'decolonisation' is not the preferred term in the document it still undertakes the decolonisation of the curricula at UP.

As Madlingozi warned, however, there is the need to confront deep-rooted legacies of racial exclusion and cultural domination

51 Yancy (n 45 above) 4.

52 Madlingozi (n 49 above) 33.

53 Madlingozi (n 49 above) 29. 
within universities, and in particular within law faculties. ${ }^{54}$ So, even if one has switched from violence to acceptance - from resistance of calls for decolonisation of universities, to the drawing up of framework policies, the white gaze will persist in transformation efforts where it is not confronted and dismantled. Whiteness will simply centre itself once again in the project of decolonisation. ${ }^{55}$ To merely tolerate the call for decolonised education, and accept a lower standard thereof (or accept a less radical and committed transformation), is to maintain the power of the white gaze where the lives, the well-being, and the futures of black students merely exist in the imagination of (white) academics who make the call on what is included in the curriculum. 